\title{
SISTEMATIZAÇÕES TEÓRICAS FUNDAMENTAIS. QUAL SUSTENTABILIDADE É PRECISO, E QUAL EDUCAÇÃO AMBIENTAL NOS LEVARÁ ATÉ ELA?
}

\author{
João Paulo Peres Bezerra ${ }^{1}$
}

\begin{abstract}
RESUMO: O texto aqui exposto apresenta sistematizações teóricas voltadas ao melhor entendimento das matrizes teóricas do conceito de sustentabilidade e as concepções de educação ambiental mais presentes no atual debate. Temos como objetivo maior subsidiar reflexões para os interessados no tema, tendo em perspectiva um melhor alinhamento entre o universo teórico conceitual e a práxis inerente aos fazer educação ambiental. Em uma primeira parte apresentamos uma sistematização realizada por (BOFF, 2012), onde encontramos uma síntese das atuais matrizes teóricas que subsidiam o conceito de sustentabilidade. Em uma segunda parte, apresentamos a sistematização elaborada por (RODRIGUEZ e SILVA, 2013), cuja obra apresenta uma sistematização das concepções atuais de educação ambiental. Assim pretendemos subsidiar uma reflexão elementar a ser realizada pelos interessados, tendo em perspectiva um alinhamento teórico conceitual e político para os envolvidos com Educação Ambiental. Ressaltamos que o esse texto se insere no contexto da pesquisa de doutoramento intitulada 'Gestão Integrada de Resíduos Sólidos Urbanos Municipais: Interfaces concretas e novas potencialidades, e é realizada no programa de pós-graduação em Geografia da UNESP- FCT de Pres. Prudente, sobre orientação do Prof. Dr. Antonio Cezar Leal.
\end{abstract}

PLAVRAS CHAVE: sustentabilidade; educação ambiental; crise socioambiental

\section{SYSTEMATIZATIONS FUNDAMNTAL THEORY. WHAT SUSTENABILITY IS NEEDED, AND ENVIRONMENTAL EDUCATION WHICH WILL TAKE US TO HER?}

\begin{abstract}
The text displayed here has focused on the better understanding of the theoretical frameworks of sustainability theoretical systematization and conceptions of environmental education more present in the current debate. We have to subsidize higher reflections for those interested in the subject, taking into perspective better alignment between the conceptual and theoretical universe praxis inherent to environmental education. In a first part is a classification performed by (Boff, 2012), where we find a synthesis of current theoretical frameworks that support the concept of sustainability. In a second part, we present a systematization developed by (and RODRIGUEZ SILVA, 2013), whose work presents a classification of the current conceptions of environmental education. So we intend to subsidize an elemental being held by stakeholders reflection, taking into perspective a conceptual and political theorist alignment for those involved with environmental education. We emphasize that this text
\end{abstract}

\footnotetext{
Mestre e Doutorando em Geografia- Área de Concentração (Análise Ambiental). Desenvolve trabalhos como consultor técnico e na docência em nível universitário. Como pesquisador atual no grupo de pesquisa GADIS da UNESP FCT de Presidente Prudente. Contatos: email: ipp bezerra@hotmail.com / 18991398989.
} 


\title{
¿SISTEMATIZACIONES TEÓRICAS FUNDAMENTAIS. QUE SUSTENTABILIDAD ES NECESSÁRIA, Y QUE EDUCACIÓN AMBIENTAL QUE NOS LLEVARÁ A ELLA?
}

\begin{abstract}
RESUMEN: El texto que se muestra aquí características destinadas a una mejor comprensión de los marcos teóricos de la sostenibilidad sistematización teórica y concepciones de la educación ambiental más presentes en el debate actual. Nuestro objetivo es subsidiar reflexiones más altos para las personas interesadas en el tema, teniendo en perspectiva de una mejor alineación entre el universo conceptual y teórico praxis inherente a la educación ambiental. En una primera parte es una clasificación realizada por (Boff, 2012), donde nos encontramos con una síntesis de los marcos teóricos actuales que apoyan el concepto de sostenibilidad. En una segunda parte, se presenta una sistematización desarrollada por (y RODRIGUEZ SILVA, 2013), cuya obra presenta una clasificación de las concepciones actuales de la educación ambiental. Así que tenemos la intención de subvencionar un ser elemental en poder de las partes interesadas la reflexión, teniendo en perspectiva de un alineamiento teórico conceptual y política para los involucrados con la educación ambiental. Hacemos hincapié en que este texto está en el contexto de la investigación doctoral titulada "Gestión Integrada de Residuos Sólidos Municipales: Interfácies Concrete y nuevas capacidades, y se mantiene en el programa de postgrado en Geografía UNESP FCT Pres. Cuidado con la dirección del Profesor Phd. Cezar Leal.
\end{abstract}

PALABRAS CLAVE: sostenibilidad; educación ambiental; crisis ambiental

\section{APRESENTAÇÃO}

O texto aqui apresentado busca expor um caminho de reflexão para aqueles que buscam melhor entender seus próprios posicionamentos como educadores ambientais. Em uma primeira parte apresentamos uma sistematização realizada por (BOFF, 2012), onde encontramos uma síntese das atuais matrizes teóricas que subsidiam o conceito de sustentabilidade. Em uma segunda parte, apresentamos a sistematização elaborada por (RODRIGUEZ e SILVA, 2013), cuja obra apresenta uma sistematização das concepções atuais de educação ambiental. Assim pretendemos subsidiar uma reflexão elementar a ser realizada pelos interessados, tendo em perspectiva um alinhamento teórico conceitual e político para os envolvidos com 
Educação Ambiental. Ressaltamos que o esse texto se insere no contexto da pesquisa de doutoramento intitulada 'Gestão Integrada de Resíduos Sólidos Urbanos Municipais: Interfácies concretas e novas potencialidades, e é realizada no programa de pós-graduação em Geografia da UNESP- FCT de Pres. Prudente, sobre orientação do Prof. Dr Antonio Cezar Leal.

\section{A CONJUNTURA ATUAL}

Os avanços técnicos, científicos e informacionais realizados pela civilização após o lluminismo, chegando até os dias atuais, proporcionaram a expansão irracional da industrialização e da urbanização, causando problemas significativos e muito debatidos atualmente. Deixando um olhar atento a nossa volta, podemos perceber um significativo desequilíbrio nas relações do homem e seu meio natural, nota-se, um conjunto de conflitos e tensões que permeia a escala global e muitas vezes entram em erupção na escala local. Entramos no século XXI com um grande conjunto de problemas a serem superados pela comunidade planetária, vivendo tempos de incertezas e ameaças, advindas do que chamamos popularmente de problemas ambientais.

Em nosso viver cotidiano as questões ambientais são comumente colocadas pela grande mídia, como os desafios estruturais a serem superados pela sociedade contemporânea. Os impactos e as situações de degradação ambiental têm sua origem no atual modo de vida e, sem dúvida, na irracionalidade do atual sistema econômico, este que se apresenta sob uma lógica de acumulação imediatista concentrando poder, renda e oportunidades.

Concentração de renda extrema, locais inadequados para a deposição final de resíduos, canais fluviais assoreados, desmatamento ilegal, poluição de corpos hídricos, intensificação da especulação imobiliária e a expansão de moradias irregulares, a perda de diversidade genética da biota, uso irracional dos recursos minerais, trabalho análogo à escravidão, aumento das médias das temperaturas máximas na escala global, a lixiviação e contaminação de solos, poluição atmosférica 
automotiva e industrial, a contaminação dos alimentos por defensivos agrícolas e muitos outros exemplos possíveis perfazem o cenário atual de crise socioambiental.

Lembremos-nos da Carta da Terra, um dos mais importantes e fascinantes documentos internacionais contemporâneos, voltada a questões ambientais e sociais -socioambientais. Elaborada por pensadores como o brasileiro Leonardo Boff, Michael Gorbachev, Steven Rockfeller, Maurice Strong, Mercedes Sosa, que ainda em seu preâmbulo, explícita um alerta para os pensadores, gestores e educadores contemporâneos, vejamos.

\begin{abstract}
Estamos diante de um momento crítico da história da Terra numa época que a humanidade deve escolher o seu futuro [...]. A escolha é nossa deve ser: ou formar uma aliança global para cuidar da Terra e cuidar dos outros, ou arriscar a nossa destruição e a destruição da diversidade da vida. (Carta da Terra, preâmbulo).
\end{abstract}

Observando o trecho citado, podemos sentir o teor e a magnitude do problema a ser superado pelos povos da Terra, e é nesta perspectiva que norteamos nossos trabalhos. Tendo nas ações do agora a aposta para os resultados do amanha. Temos um vasto campo de atuação, seja nos segmentos mais voltados a iniciativas e inovações técnicas ou no campo do debate e construção teórica, ou ainda no campo da Educação Ambiental que deve contemplar as questões técnicas e teóricas voltados à construção de uma nova maneira do viver.

Nesta perspectiva, a palavra sustentabilidade, surge no senso comum como algo mágico que pode vir a solucionar nossos dilemas socioambeintais. Porém, observando mais atentamente, é possível perceber que a atual ordem do sistema econômico-financeiro, mostra-se impreterivelmente insustentável.

Compactuando da perspectiva exposta acima, o verbete: sustentabilidade, se perde em meio a um caleidoscópio de significados. Assim é necessário mantermos o foco na capacidade de uma sociedade em viabilizar a inclusão de todos e garantirIhes os meios de uma vida suficiente e decente, com esta simples concepção já é possível perceber a necessidade de mudança em nossas relações do cotidiano banal na busca de uma efetiva sustentabilidade. (BOFF, 2012, p. 19-20). 
Tal empreita requer profundas mudanças culturais, e para tanto, temos na Educação Ambiental uma ferramenta, um instrumento de superação de padrões culturais degradantes. Acreditamos que a via da Educação Ambiental foi, ainda é e será o caminho para a superação da atual crise socioambeintal, porém os trabalhos engajados devem ter em mente a necessidade de clareza conceitual interna aos projetos e trabalhos de educação ambiental.

Educadores, gestores, líderes comunitários e formadores de opinião, que busquem na educação ambiental um meio de militância ou ação engajada, são agentes importantes no processo de construção, de uma nova maneira de se relacionar com o mundo. Nesta caminhada, é fundamental, que façamos uso do significativo conjunto de teorias e técnicas já existentes, seja para elaboração de críticas construtivas ou para a adoção e uso do instrumental teórico conceitual, que subsidie uma maior qualificação dos debates e enfrentamentos a serem realizados ao longo da vida dos educadores.

Frente a estas premissas, acreditamos ser importante trazermos apontamentos teóricos sobre o termo sustentabilidade e sobre as perspectivas atuais da educação ambiental. Para tanto temos dois trabalhos centrais observados neste texto: (BOFF, 2012) que traça uma síntese das concepções sobre o conceito de sustentabilidade e desenvolvimento sustentável e (RODRIGUEZ; CAVALCANTI, 2013) onde temos uma sistematização das concepções atuais de educação ambiental.

É fundamental, que os agentes fomentadores da Educação Ambiental tenham claramente definidos quais são os fundamentos e premissas teóricas sobre o conceitos que norteiam seus projetos, oficinas ou suas disciplinas regulares de educação ambiental.

\section{A SUSTENTABILIDADE E SUAS MATRIZES!}

$\mathrm{Na}$ raiz da palavra sustentabilidade temos o verbo latino sustentare, ou 'sustentar' em português. Buscando uma referencia sobre a gênese da ideia de 
sustentabilidade no sentido ligado ao debate ambiental, encontramos a nos escritos de (BOFF, 2012, p. 32-33) a citação abaixo, vejamos:

\begin{abstract}
Mas foi na Alemanha, em 1560, na Província da Saxônia,que irrompeu, pela primeira vez, a preocupação pelo uso racional das florestas, de forma que elas pudessem se regenerar e se manter perenemente. Neste contexto surgiu a palavra alemã Nachhaltigkeit que traduzida significa "sustentabilidade.
\end{abstract}

Neste mesmo contexto, buscando equilibrar a utilização de recursos madeireiros com sua disponibilidade futura, foi que em 1713, novamente na região da Saxônia surgem, sistematizações acadêmicas, utilizando a palavra sustentabilidade Nachhaltigkeit. Tal estudo foi elaborado pelo militar Hans Carl Von Carlowitz, tendo como lema: man muss mit Holz pfleglich umgehe - 'devemos tratar a madeira com cuidado, caso contrário acabar-se-á e cessará o lucro. Esta corrente foi tão forte que resulta no surgimento de uma nova disciplina cientifica, a silvicultura. (BOFF, L. 2012)

Muitas décadas depois, temos o relatório entitulado Os Limites do Crescimento que explicita os limites dos recursos naturais e assim os limites para o desenvolvimento da civilização. Passados alguns anos publica-se em 1988 a primeira edição do relatório Our Commom future. O relatório Nosso Futuro Comum traz claramente um definição do que seria o Desenvolvimento Sustentável, com as seguintes palavras, "O desenvolvimento sustentável é aquele que atende às necessidades do presente sem comprometer a possibilidade de as gerações futuras atenderem a suas próprias necessidades" (CNUMAD, 1991, p. 46). No interior da compilação do conceito de desenvolvimento sustentável temos claramente dois pontos estruturais, vejamos:

\footnotetext{
- o conceito de "necessidades", sobretudo as necessidades essenciais dos pobres do mundo, que devem receber a máxima prioridade;

- a noção das limitações que o estágio da tecnologia e da organização social impõe ao meio ambiente, impedindo-o de atender as necessidades presentes e futuras. (CNUMAD, 1991, p. 46).
}

Assim, temos com clareza uma premissa, que deve nortear os trabalhos iniciais em possíveis projetos e situações de Educação Ambiental. Tal premissa, ao nosso entender, explicita a pobreza e a desigualdade social, como um problema 
ambiental a ser superado. Assim acreditamos que esta premissa deva ser efetivamente internalizada pelos agentes envoltos à educação ambiental. Explicitamos esta ideia, pois queremos elucidar a multiplicidade dos entendimentos sobre o conceito de desenvolvimento sustentável e a significação conceitual da palavra sustentabilidade.

Seguimos então com este objetivo, e para tanto gostaríamos de mostra uma interessante abordagem elaborada por Leonardo Boff em 2012. Trazemos esta abordagem, pois acreditamos que as intencionalidades dos diversos agentes envolvidos com a Educação Ambiental, possam encontrar suas identificações com as mesmas e assim melhorar suas argumentações e fundamentações a partir dos nove modelos elencados por Boff (2012), que sintetizam de maneira didática a polissemia inerente ao termo em questão.

Iniciando com a corrente chamada pelo autor como Sustentabilidade retórica, onde o sentido dos termos desenvolvimento sustentável e sustentabilidade habilmente desvia o olhar para os reais problemas como injustiça social nacional e mundial. Aqui a perspectiva maior esta na preservação da natureza para seu uso no futuro e busca através de temas banais a fim de manter uma visão distorcida do real problema.

Outro modelo que merece nossa atenção é o modelo Neocapitalista que delega o mínimo poder regulatório ao Estado, deixando o mercado navegar conforme suas próprias cartas, e assim o sentido de sustentabilidade neste contexto se esvazia por inteiro, entendendo as adequações e regulações como empecilhos à lógica produtiva. Concomitante mas não contrário, temos similaridades agrupadas pelo autor supracitado nos modelos: capitalismo natural e a sustentabilidade enganosa e modelo da economia verde e sua sustentabilidade fraca. No primeiro, a ideia de dominar a natureza permanece como nos outros modelos já citados, com discursos voltados às inovações tecnológicas e novas roupagens teóricas concebem a premissas que visam guardar os recursos naturais para serem utilizados no futuro.

Já no modelo da Economia Verde, tem sua origem nas dificuldades do setor químico industrial durante o pós-guerra, uma vez que sua cadeia produtiva estava voltada à produção bélica, e então ao fim de seu principal mercado, a guerra, passa a 
focar seus esforços na agricultura. Este modelo merece nossa atenção, uma vez que possui grande força geopolítica, suas teorias centrais, foram apresentadas, em 2009, por Ban Kin Moon e pelo Sr. Albert Arnold Gore Júnior. Neste modelo temos o auxílio aos menos favorecidos por meio do oferecimento de semente e defensivos agrícolas e conjunto com linhas de financiamentos. A sustentabilidade se pulveriza nos esforços de mitigação de impactos, que buscam uma economia de baixo-carbono e a proteção da biota é expressa pela clássica criação de parques entre outras medidas mitigadoras. Mas, novamente o cerne da questão não é contemplado no modelo da economia verde chamada pelo autor em questão de sustentabilidade fraca. (BOFF, 2012)

Os cinco modelos já destacados, marcam as concepções voltadas ao mantenimento da ordem global, que nos oferece uma civilização industrial pautada na exploração do trabalho e da natureza. Tal lógica gera uma série de problemas ambientais e sociais delegando, à nossa geração e as gerações futuras, um cenário de crise socioambeintal ainda mais intenso. Os próximos quatro modelos, trazem, perspectivas de transformação efetiva da sociedade, ainda que utópicas e sem experiências concretas de aplicação, tais modelos devem nortear nossos trabalhos e posicionamentos frente ao desafio posto pela crise socioambiental.

O Ecossocialismo nasce como "uma corrente de pensamento e de ação ecológica que traz seus argumentos fundamentais do marxismo, mas ao mesmo tempo, o livra de suas escórias produtivistas" (LOWY, 2005, p. 47), propondo uma superação da lógica do mercado e do lucro irracional do capitalismo, e também, se opõem à lógica do burocrático do estado de ferro do socialismo real, pois ambas são incompatíveis com a preservação do meio ambiente natural e devem ser superadas. Nesta corrente teórica podemos destacar os trabalhos de: James O'Corner, Barry Commoner, Jhon Bellamy Foster, Joel Kovel, Juan Martinez Allier, Francisco Fernandez Buey, Jorge Reichaman, Jean Paul Déléage, Jean-Marine Harribey, Elmar Altvater, Frieder Otto Wolf. Estes são os protagonistas do debate internacional que se veicula principalmente pelos periódicos: Capitalism, Nature and Socialism; Ecologia Política, como nos comunica Michael Lowy (2005, p. 48). 
Este modelo ainda não teve sua implantação concreta e se apresenta como uma proposta ainda na executada. Fundamentada em valores não monetários como a justiça social, a equidade, no valor do uso ao invés do valor de troca, na transformação dos critérios político-econômicos quantitativos para critérios qualitativos. Tal corrente afirma que os recursos naturais como: o solo fértil, o ar puro, o acesso aos recursos hídricos e o acesso universal aos alimentos livre de contaminação por agrotóxicos pertencem aos direitos naturais e básicos de todos os seres humanos. (BOFF, 2012, p. 57).

Outra vertente possível é a chamada Bioeconomia ou ecodesenvolvimento, cuja noção de sustentabilidade se ancora no "decrescimento econômico para a sustentabilidade ambiental e equidade social”. (BOFF, 2012, p. 57). Aqui a economia deve seguir o ritmo e os limites da natureza e não apenas a lógica do mercado. Este modelo sincroniza os trabalhos os trabalhos de Ignacy Sachs, que promulga ser impossível termos um conceito de sustentabilidade que não contemple o fim da desigualdade social, participação popular na construção da democracia e um cuidado permanente com o meio ambiente. Tendo a centralidade teórica na vida humana e não na busca do lucro ou acumulação e concentração advindos da ganância cega da concorrência. No Brasil o expoente desta vertente, é o Professor Ladislau Dowbor, propondo uma democracia econômica em DOWBOR (2008).

O modelo da Economia solidaria: a microsustentabilidade viável. Apresenta-se como uma solução viável, principalmente na escala local. Tendo suas fundamentações na teoria da Economia Solidária, criada pelo grande pensador Paul Singer. Tem nas obras: Introdução à economia Solidária de 2002 e Economia Solidária no Brasil de 2003, duas grandes referencias para maiores detalhamentos. Suas premissas se resumem nas seguintes palavras:

Neste tipo de economia o centro fulcral é ocupado pelo ser humano e não pelo capital, pelo trabalho como ação criadora e não como mercadoria paga pelo salário, pela solidariedade e não pela competição, pela auto gestão democrática e não pela centralização de poder dos patrões, pela melhoria da qualidade de vida e do trabalho e não pela maximização do lucro, pelo desenvolvimento local em primeiro lugar e, em seguida, o global. (BOFF, 2012, p.60). 
Outra teoria que se conecta a este modelo é a Teoria da Utilização Progressiva, criada pelo filósofo indiano Prabahat Sakar em 1998, que propõe uma economia dinâmica do povo, pelo povo e para o povo. A teoria de Sakar tem como proposta geral a busca do desenvolvimento integral do ser humano em sua dimensão física, mental e espiritual, a partir da resistência ao materialismo excessivo que produz uma série de resultados negativos. Esta teoria se alinha à Economia Solidária por eleger o cooperativismo como forma comum de superação das atuais relações de mercado.

No Brasil, pode ser observado nas cooperativas de produtores campesinos, cooperativas de catadores de materiais recicláveis, nas trocas comerciais de sementes crioulas, cooperativas de extração de produtos da floresta pelas comunidades ribeirinhas, quilombolas e povos cerradeiros.

Enfim, o autor chega à chamada por ele como: Sustentabilidade Desejável. Sua matriz se encontra no modo de vida dos povos andinos onde o foco da comunidade esta no equilíbrio e na centralidade da vida. Assim o ser humano é uma parte integrante da chamada comunidade terrenal, em conjunto indissociável das montanhas, do Sol e da Lua, dos animais, das plantas do ar e da água. (BOFF, 2012, p 62).

Com estas colocações, acreditamos ter exposto uma síntese eficaz sobre as atuais matrizes conceituais do conceito multifacetado de sustentabilidade. Partimos então para uma observação sobre as concepções de Educação Ambiental.

\section{QUAL É A SUA EDUCAÇÃO AMBIENTAL?}

Todos os envolvidos na construção e aplicação do processo, que chamamos de Educação Ambiental, sejam eles: formadores de opinião inseridos na mídia, professores da rede educacional formal, gestores inseridos no sistema de gestão ou 
lideranças políticas; precisam refletir sobre qual é a fundamentação teórica que sustenta os seus trabalhos.

Para realizar este exercício, de reflexão dialética, é necessário um olhar atento, para sabermos por onde estamos caminhando e onde este caminho nos levará! $\mathrm{Na}$ tentativa de contribuir para o debate, iniciamos explicitando um questionamento incisivo e muito claro realizado por (RODRIGUEZ \& SILVA, 2013, p. 175), que nos mostra a importância desta reflexão, vejamos:

A pergunta fundamental é: Por que é necessário projetar e instrumentar um tipo específico de educação, em particular a educação ambiental? A resposta é que a humanidade e o Planeta Terra, no qual ela vive estão emersos em uma profunda crise civilizatória de caráter ambiental e que, de uma forma ou de outra, afeta todos os sistemas locais e regionais, incluindo seus grupos sociais.

Assim, admitimos em nossos posicionamentos a premissa de estarmos imersos em uma crise socioambiental, cujo instrumento fundamental de superação é a educação ambiental. Mas, temos de ter em mente, qual é a concepção de educação ambiental que adotamos como base em nossos projetos e ações.

Para iniciarmos esta reflexão, necessitamos de uma sistematização sobre as possíveis correntes de Educação Ambiental presentes no debate contemporâneo. Observando a literatura específica, propomos uma atenta observação aos quatro modelos/concepções de educação ambiental identificados, em 2013, pelos professores José Manuel Mateo Rodriguez e Edson Vicente da Silva.

Os autores em questão iniciam sua análise expondo um importante posicionamento, onde colocam a educação ambiental, como instrumento para a superação, do que chamamos aqui de crise socioambiental, vejamos:

A educação ambiental surge como uma necessidade no processo de salvar a humanidade de seu próprio desaparecimento e de ultrapassar a crise ambiental contemporânea. É um dos meios para se adquirir as atitudes, as técnicas e os conceitos necessários à construção de uma nova forma de adaptação cultural aos sistemas ambientais. É, também, um elemento decisivo na transição para uma nova fase ecológica, que permita ultrapassa a crise atual, através de qual seja transmitido um novo estilo de vida e que se 

dominantes na sociedade atual. (RODRIGUEZ \& SILVA, 2013, p. 176).

Como podemos observar na citação acima, a educação ambiental é estrutural para uma efetiva mudança da atual maneira de viver. $E$ aqui reside a sua verdadeira importância. Neste cenário faz-se importante, cada vez mais, que os educadores ambientais busquem um posicionamento efetivo e embasado teoricamente. Para tanto podemos começar pela observação das atuais correntes de educação ambiental. Esta tarefa é facilitada quando observamos os trabalhos de, RODRIGUEZ \& SILVA (2013) que trazem uma sistematização muito acertada sobre as atuais concepções de educação ambiental.

A primeira concepção apresentada pelos autores é chamada de Educação Ambiental Tecnicista. Seus fundamentos teóricos se encontram no que os autores chamam de educação tecnocrática, tendo como principal ferramenta, a transmissão de conteúdos sistematizados e responde a demandas profissionalizantes de uma sociedade de mercado. Tal perspectiva esta comprometida com 'a reprodução de valores do sistema capitalista vigente, tendo laços estreitos com o aparato produtivo' (RODRIGUEZ \& SILVA, 2013, p. 178). Aqui o conceito de natureza, se limita, a entendê-la como uma fonte de recursos naturais a serem apropriados pelo sistema de produção vigente. Esta concepção é sempre associada a premissas neoliberais e considera não ser necessária uma mudança no sistema sociopolítico, reproduzindo em seus discursos teóricos valores como o eficientismo, a competitividade e o utilitarismo. (RODRIGUEZ \& SILVA, 2013).

A segunda concepção é a Educação Ambiental Comportamental. Nesta corrente temos como base pedagógica científica o behaviorismo, e busca a construção da racionalidade ambiental como objetivo final dos processos de educação ambiental. Outro objetivo desta vertente é a mudança na relação sociedade-natureza, buscando a transformação dos hábitos em curto prazo. Esta concepção é sintetizada pelos autores nas seguintes palavras.

Esta visão de educação ambiental é característica da corrente do ambientalismo pragmático que, embora considere ser necessário manter, sem mudar estruturalmente o sistema capitalista, parte da ideia de que 
apenas as mudanças tecnológicas não são suficientes; que é necessário, além disso, introduzir o controle estatal do mercado e influenciar na mudança dos comportamentos, dos estilos de vida e dos hábitos de consumo dos seres humanos, limitando o consumismo. (RODRIGUEZ \& SILVA, 2013, p. 180).

Com a citação acima, podemos perceber as matrizes da concepção em questão. Ressaltamos que esta visão contempla questões fundamentais para a superação da atual crise socioambiental, mas, ainda se ancora nos elementos das teorias desenvolvimentistas, e assim, não tem como premissa, a superação das causas centrais da atual crise.

Outra concepção é chamada de Educação Ambiental Ética, tem como perspectiva internalizar, no processo de educação ambiental, um posicionamento ético frente ao universo subjetivo dos indivíduos e da cultura. Os encaminhamentos estão voltados a fomentar mudanças na sensibilidade dos seres humanos, dando luz à razão intuitiva, ao imaginário, buscando sanar as necessidades espirituais dos envolvidos.

Esta vertente se conecta as correntes da ecologia profunda e da ecologia social, busca a construção de uma sociedade livre, em harmonia com a natureza e o mercado pautada na equidade social. Aqui, a comunidade exerce um papel central nos processos de apropriação da natureza e da gestão ambiental, com foco continuo na justiça social a partir de processos de desenvolvimento local e regional. Tal concepção é uma posição ético-filosófica, para a educação ambiental, que busca elaborar uma análise crítica do padrão da sociedade, buscando a construção de uma sociedade socialista, pautada na harmonia com seu ambiente no princípio da igualdade social RODRIGUEZ \& SILVA (2013).

Enfim, temos a Educação Ambiental Ético-Social, também compromissada com a formação crítica do indivíduo, buscando "[...] a aquisição de um sistema amplo e dinâmico de conhecimento que seriam adquiridos não somente na escola" RODRIGUEZ \& SILVA (2013, p. 181), mas sim em todos os processos de vivencia.

Nesta concepção o foco se encontra na formação de indivíduos críticos que sejam capazes de identificar problemas coletivos, de auto-organização, que gradativamente venham elaborar processos de superação da atual crise ambiental. Construindo uma sociedade que tenha como premissa os princípios da igualdade, da 
democracia participativa e sustentável, privilegiando as políticas sociais e o planejamento regulador e o papel estrutural com conceito da propriedade social. RODRIGUEZ \& SILVA (2013).

Temos então uma concepção que ainda se encontra apenas no campo teórico e talvez como algo a ser tido como uma situação ideal, mas que deve ser observada com atenção esta concepção. Uma vez que esta pode vir a ser um norte para os futuros debates sobre Educação Ambiental. Para tanto gostaríamos de apresentar uma síntese do conjunto de valores expressos por (LOPES SARAIEGO, 1994 apud RODRIGUEZ \& SILVA, 2013) quando explicitam os princípios da pedagogia ambiental que norteia a concepção de educação ambiental em questão. Tais princípios, por nós sintetizados e adaptados, são expressos nas palavras abaixo:

- A Educação Ambiental deveria atravessar todo o processo educacional, como uma modalidade transdisciplinar;

- No processo educacional temos de focar a participação dos estudantes nos processo de construção e socialização do conhecimento. Sempre tendo em perspectiva, uma articulação entre ação-investigação-educação que deve permanecer além das esferas da escola;

- Apresentar o processo de conhecimento de forma que se superem os dogmas. Viabilizando um processo educacional como um processo permanente e multdirecional;

- Elaborar uma articulação efetiva entre a educação formal e informal, tendo no conhecimento científico o instrumento de compreensão do atual momento de crise;

- Reconhecer que o conhecimento não deve ser entendido como algo finalizado e pronto. Mas sim como um processo permanente de crescimento, revisão e aprofundamento. Buscando soluções construídas a partir da participação e democratização;

- Vincular a Educação Ambiental aos temas cotidianos tendo na participação efetiva da sociedade a força motriz para melhorias ambientais e processos educacionais;

- Ter como meta, a construção da mentalidade ambiental com fundamentos: holísticos, sistêmicos, integradores e que permitam a maior probabilidade de temas e questionamentos possíveis. Sempre direcionada ao pensamento crítico, criativo e prospectivo. Milbrath (1996);

- Construir a Educação Ambiental para o desenvolvimento sustentável, contemplando a diversas concepções deste conceito, sincronizando os princípios e valores com suas matrizes conceituais no processo educacional;

- Conceber as diversas categorias da educação como: formal, escolar, comunitária, de capacitação e formação ambiental. E a partir desta multiplicidade buscar adaptações de conteúdo e funções;

- Fomentar a Pedagogia Ambiental com bases no conceito de cultura ambiental. (LOPES SARAIEGO, 1994 apud RODRIGUEZ \& SILVA, 2013, p. 181-183). 
Tais princípios, expressos na síntese acima, fomentam a elaboração de uma base teórico-filosófica, para a construção de uma educação ambiental que supere as visões reducionistas e tecnicistas, buscando a efetiva construção de uma corrente educacional que se harmonize com uma racionalidade ambiental. Neste campo do debate, faz-se importante ressaltar algumas obras teóricas, que direta ou indiretamente, fundamentam o discurso da racionalidade ambiental, vejamos algumas obras elementares: Enrique Leff (2008, 2003, 2001); Edgar Morim (1996a, 1996b, 1991) entre muitos outros pensadores.

Neste sentido, caminhamos para a construção de uma nova pedagogia, com suas bases e práticas, reformuladas em busca da incorporação da dimensão ambiental nos diversos processos educacionais. (RODRIGUEZ \& SILVA, 2013). Reforçando esta perspectiva temos as palavras de Cascino (2000), vejamos:

\footnotetext{
Uma pedagogia com base na expressão profunda das ambiguidades do processo e daqueles que produzem educação -revelando erudição e vivência, essência e existência, o fugaz e o etéreo- tem como meta inaugurar um fazer educação que considere as diferenças, as iniciativas autônomas, que respeite as ações e reflexões que ocorrem e se articulam fora dos espaços "controlados". (CASCINO, 2000, p. 83).
}

Fabio Cascino, o autor em questão, ressalta a possibilidade de incorporar a diferença no debate, a partir de pautas e temas, como: "pesquisa, rigorosidade metódica, ética, criticismo, estética, autonomia, bom-senso, humildade, tolerância, curiosidade, comprometimento, liberdade, autoridade, diálogo, o querer bem". (CASCINO, 2000, p. 83). Tais premissas, por sua vez, têm suas raízes na pedagogia da autonomia, do mestre Paulo Freire. (FREIRE, 1997).

\section{CONSIDERAÇÕES FINAIS}

Com as colocações explicitadas no texto, não pretendemos moldar um debate ou engessar as ações futuras de educadores ambientais. Mas sim, subsidiar uma reflexão libertadora a partir do conhecimento das matrizes expostas. A partir das considerações realizadas pelos autores presentes neste texto, acreditamos, que os 
leitores engajados com a Educação Ambiental poderão realizar uma auto-reflexão sobre seu trabalhos podendo reafirmar seus posicionamentos ou corrigir a rota de seus caminhos.

\section{REFERENCIAS}

CASCINO, F. Educação Ambiental: princípios, história, formação de professores. São Paulo: Editora SENAC São Paulo, 2000.

CARTA DA TERRA. Carta da Terra. Disponível em < http://www.cartadaterrabrasil.org/prt/history.html $>$ Acesso em 02/05/2013.

CNUMAD. Nosso Futuro Comum. 2 ed. Rio de Janeiro: Editora da Fundação Getúlio Vargas, 1991.

FREIRE, P. Pedagogia da Autonomia: saberes necessários à prática educativa. São Paulo: Paz e Terra, 1997.

LEFF, E. A Complexidade Ambiental. 2 ed. São Paulo: Cortez, 2003.

Epistemologia Ambiental. São Paulo: Cortez, 2001.

Verde Cotidiano o Meio Ambiente em Discussão. Petrópolis: Dp et Alli, 2008.

LOWY, M. Ecologia e socialismo. São Paulo: Cortez, 2005.

MORIN, E. Os sete Saberes necessários à educação do futuro. São Paulo: Cortez, 1996a.

O problema epistemológico da complexidade. Publicações Europa-América, 1996b.

O Paradigma Perdido. Publicações Europa-América, 1991.

RODRIGUEZ, J.M.M; SILVA, E.V. Educação Ambiental e Desenvolvimento Sustentável:

Problemática, Tendências e Desafios. Fortaleza: Edições UFC, 2010.

SAKAR, P.R. Democracia Econômica: teoria da utilização progressiva. São Paulo: Ananda Marga, 1996. 